\title{
Experimental study of pine ectomycorrhizae: ectomycorrhizal organization after girdling of the hypocotyl
}

\author{
J. Lei and J. Dexheimer
}

Laboratoire de Biologie des Ligneux, J.E. CNRS 034613, Université de Nancy I, BP 239. 54506 Vandœuvre Cedex, France

Numerous authors have already described the ultrastructural organization of ectotrophic mycorrhizas in various species. In the present work, we studied how the ectomycorrhizal architecture is modified when the host plant-fungus equilibrium is disturbed, by girdling the hypocotyl of Pinus sylvestris plantlets mycorrhized by Hebeloma crustuliniforme or Paxillus involutus. This stops the flow of sugars to the roots.

We examined the changes in mycorrhizal structure and function at different time intervals.

Girdling of the host plant causes extensive changes in both partners leading morphologically in the pine to the swelling of the stem above the ablation (Fig. 1) and in the fungal partner to the more or less complete disappearance of the intramatrical mycelium (Figs. 2 and 3 ).

The swelling of the stem is characteristic of plants that have undergone girdling. The products of photosynthesis in the aerial part are blocked by girdling and can no longer migrate into the root system (Zimmermann, 1969).

This operation also induces a profound transformation of mycorrhizal structure (Figs. 4 and 5).
In about 10 days, the thickness of the mantle is reduced and its structure becomes increasingly loose. Twenty days after girdling, the mantle is replaced by a loose network which is very different from the usual mycelial sleeve (Fig. 5).

The Hartig net also has an abnormal structure (Figs. 6 and 7). Like the mantle, it becomes less dense and, in most cases, the hyphae are bordered by dead cortical cells which are often filled with tannins. Moreover, the component hyphae have an unusual behavior as they give off branches which penetrate into the host cells. Sometimes these branches penetrate dead cells and the only change is a perforation of the wall. In other cases, the branches penetrate into a living cell as shown by the existence of a parietal papilla at the penetration site (Fig. 8). Such papillae are well known in biotrophic parasitic infections (Berlin and Bowen, 1964; Heath and Heath, 1971; Littlefield and Bracker, 1972; Hohl and Stossel, 1976; Higgins and Lazarovits, 1978; Beakes et al., 1982) and are considered to be the result of a host defense mechanism.

The girdling of the host plant not only induces morphological changes but also 


\section{$742 s$}

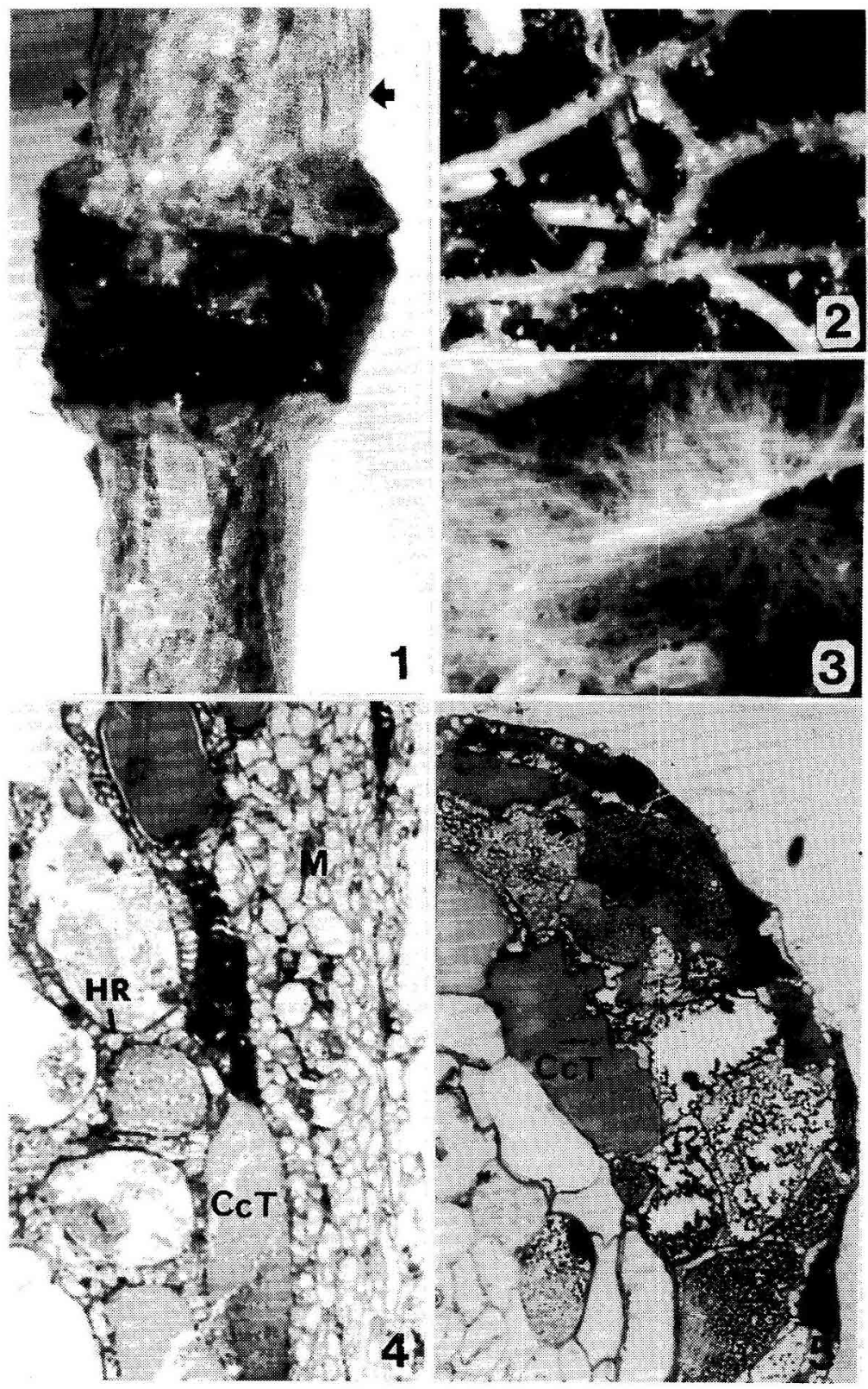

Figs. 1-5. 1. Girdling of the stem of the host plant. 2 and 3. Root system of a plantlet of $P$. sylvestris mycorrhized by $H$. crustuliniforme. 2. Girdled host plant. 3. Non-girdled host plant. 4. Semi-thin section of a mycorrhiza of a non-girdled host plant, $(G \times 590)$. 5. Semi-thin section of a mycorrhiza of a host plant 20 days after girdling $(G \times$ 420). Abbreviations: Cc: cortical cell; CcT: tannin cortical cell; Ci: interhyphal cement; HE: external hyphae; M: mantle hyphae; HR: Hartig net hyphae; M: mantle. 


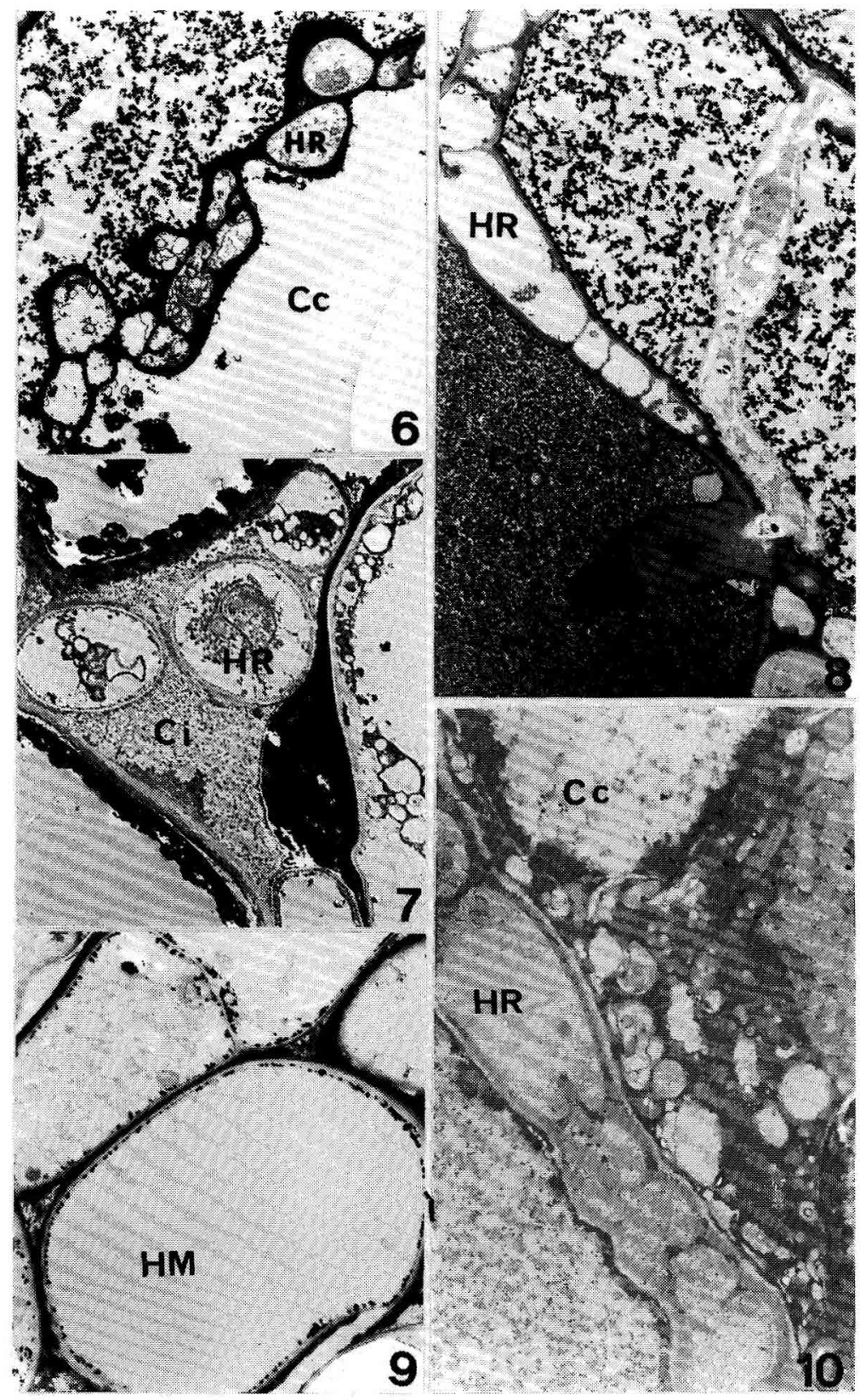

Figs. 6-10. 6. Mycorrhiza ( $P$. involutus/P. sylvestris) 14 days after girdling. Irregular Hartig net (G $\times 750)$. 7. Mycorrhiza (H. crustuliniforme/P. sylvestris) 20 days after girdling. The Hartig net has a loose structure $(\mathrm{G} \times 6600) .8$. Mycorrhiza ( $H$. crustuliniforme/P. sylvestris) 20 days after girdling. Penetration into the cortical cell ( $\star$ ) $(G \times 3300)$. 9. Mantle hyphae. ATPase activity on the hyphae plasmalemma $(G \times 74000)$. 10. Hartig net. No ATPase activity $(G$ $\times 7900)$. 
affects mycorrhizal function, as demonstrated by experiments showing the localization of ATPase activities. In a 'normal' mycorrhiza, the ATPase activities are observed on the fungal plasmalemma in the mantle and on the plasmalemma of the fungus and host cortical cells in the Hartig net (Lei and Dexheimer, 1988).

In mycorrhiza of host plants that have undergone girdling, there is no ATPase activity in the Hartig net (Figs. 9 and 10). This suggests a change in the relationship between the partners. These metabolic changes were already present before any morphological transformation.

Finally, the penetration of the Hartig net hyphae inside living cells and papilla formation suggest that, under these conditions, the fungal partner presents a parasitic type of behavior and damages cortical cells to obtain the metabolites that it requires. This interpretation is also confirmed by the more or less complete lysis of walls of cortical cells in contact with the hyphae of the Hartig net.

Hence, the alsturbance of the symbiotic equilibri:um induced by girdling of the host plant leads to a change in the structure of the mycorrhiza and a change in the relationship between the two partners from symbiosis to parasitism.

\section{References}

Beakes G.W., Singh H. \& Dickinson C.H. (1982) Ultrastructure of the host-pathogen interface of Peronospora viciae in cultivars of pea which show different susceptibilities. Plant Pathol. 31, 343-354

Berlin D. \& Bowen C.C. (1964) The host-parasite interface of Albugo candida on Raphanus sativus. Am. J. Bot. 51, 445-452

Heath M.C. \& Heath I.B. (1971) Ultrastructure of an immune and a susceptible reaction of cowpea leaves to rust infection. Physiol. Plant Pathol. 1, 277-287

Higgins V.J. \& Lazearovits G.L. (1978) Histopathological and ultrastructural comparison of Stemphylium sarcinaeforme and $S$. botryosum on red clover foliage. Can. J. Bot. 56, 2097. 2108

Hohl H.R. \& Stossel P. (1976) Host-parasite interfaces in a resistant and a susceptible cultivar of Solanum tuberosum inoculated with Phytophthora infestans: tuber tissue. Can. J. Bot. 54, 900-912

Lei J. \& Dexheimer J. (1988) Study of the basidiomycete ectomycorrhizas. Ultrastructural localization of ATPase activity in the Pinus sylvestris/Laccaria laccata association. New Phytol. 108, 329-337

Littlefield L.J. \& Eracker C.E. (1972) Ultrastructural specialization at the host-pathogen interface in rust-infected flax. Protoplasma 74, 271305

Zimmermann M. (1969) Translocation of nutrients. In: The Physiology of Plant Growth and Development. (M.B. Wilkins, ed.), McGraw-Hill, London, pp. 383-417 